\title{
Analysis of Cationic Amino Acid Transport Activity in Canine Lens Epithelial Cells
}

\author{
Hideharu OCHIAI ${ }^{1)}$, Jun MORIYAMA ${ }^{1)}$, Nobuyuki KANEMAKI ${ }^{2)}$, Reiichiro SATO ${ }^{3)}$, \\ and Ken $\mathrm{ONDA}^{4)}$ \\ ${ }^{1)}$ Research Institute of Biosciences, Azabu University, School of Veterinary Medicine, 1-17-71 Fuchinobe, Chuou- \\ ku, Sagamihara, Kanagawa 252-5201, Japan \\ 2) Animal Teaching Hospital, Azabu University, School of Veterinary Medicine, 1-17-71 Fuchinobe, Chuou-ku, \\ Sagamihara, Kanagawa 252-5201, Japan \\ 3) Laboratory of Gynecology and Obstetrics, Azabu University, School of Veterinary Medicine, 1-17-71 Fuchinobe, \\ Chuou-ku, Sagamihara, Kanagawa 252-5201, Japan \\ 4) Laboratory of Internal Medicine III, Azabu University, School of Veterinary Medicine, 1-17-71 Fuchinobe, \\ Chuou-ku, Sagamihara, Kanagawa 252-5201, Japan
}

\begin{abstract}
Cationic amino acid transport activity in a canine lens epithelial cells (LEC) line was investigated. The transporter activity of arginine was $0.424 \pm 0.047 \mathrm{nmol} / \mathrm{mg}$ protein min, while the presence of $\mathrm{N}$-ethylmaleimide, an inhibitor of the canine cationic amino acid transporter (CAT), reduced transport activity by $30 \%$. A full-length cDNA sequence of canine CAT1 was 2558 bp long and was predicted to encode the 629 amino acid polypeptides. The deduced amino acid sequence of canine CAT1 showed similarities of $92.1 \%$ and $88.6 \%$ to those of the human and mouse, respectively. Western blot analysis detected a band at $70 \mathrm{kDa}$ in a membrane protein sample of LEC. RT-PCR analysis confirmed that CAT1 was ubiquitously detected in all tissues examined.

Key words: CAT1, cDNA sequence, distribution, lens epithelial cells
\end{abstract}

\section{Introduction}

Many amino acid transport systems have been distinguished based on differences in their substrate selectivity, ion-dependence, $\mathrm{pH}$ sensitivity, kinetics and regulatory properties, using membrane vesicle preparations or cultured cells $[3,4]$. Among them, system $\mathrm{y}^{+}$was designated as a transporter of $\mathrm{Na}^{+}$-independent cationic amino acids. This designation is now attributed to what are termed cationic amino acid transporters (CAT), which belong to the SLC7 gene family. The family of CAT comprises four members, CAT1, CAT2A, CAT2B and $C A T 3$, all of which exhibit a nearly identical substrate pattern for cationic L-amino acids [7, 11]. CAT2A and $C A T 2 B$ are splice variants that differ only in a stretch of 42 amino acids $[5-8,17,19]$. CAT1 is ubiquitously expressed except in the liver. $C A T 2 A$ is observed in the liver, skeletal muscle and pancreas, while $C A T 2 B$ is an inducible isotype in many cell types. CAT3 is observed in thymus, ovary, testis, and brain.

The prominent effect of proinflammatory cytokines is to induce cells expressing the inducible isoform of the nitric oxide synthase (NOS) family, the iNOS, which results in nitric oxide (NO) synthesis [15]. High production of NO functions as a local defense against bacteria [21]. This has been demonstrated in resistance to Pseudomonas aeruginosa ocular infection at the ocular surface [14]. A precursor for the synthesis of NO is the semi-essential amino acid L-arginine, which serves also as a component for protein synthesis. L-arginine becomes limited in inflammation because of the substrate competition between high iNOS expression and arginase

(Received 7 January 2013 / Accepted 30 April 2013)

Address corresponding: H. Ochiai, Research Institute of Biosciences, Azabu University, 1-17-71 Fuchinobe, Chuou-ku, Sagamihara, Kanagawa 252-5201, Japan

(C)2013 Japanese Association for Laboratory Animal Science 
(required for protein synthesis). Transport of L-arginine into the cell is enabled primarily by CAT.

Lens epithelial cells (LECs) are the progenitors of the lens fibers in vivo and undergo a developmental transition into fiber cells of the lens cortex, a process characterized by distinct biochemical and morphologic changes such as the synthesis of crystallin proteins, cell elongation, loss of cellular organelles, and disintegration of the nucleus [2]. In spite of the importance of cationic amino acids on the ocular surface, little information is available regarding cationic amino acid transport activity in canine LECs. Previously, we developed a lens epithelial cell line originated from a mature cataract of a dog and reported several characteristics of this cell line [18]. In the present study, we investigated the cationic amino acid transport activity of the lens epithelial cell line and determined the cDNA sequence of canine CAT1 as the first step in clarifying the relationship between $C A T$ and the cationic amino acid metabolism on the canine ocular surface.

\section{Materials and Methods}

\section{Animal and cell samples}

All experiments were performed according to the guidelines of the Laboratory Animal Care Committee of Azabu University, and were in compliance with the Fundamental Guidelines for Proper Conduct of Animal Experiment and Related Activities in Academic Research Institutions. The canine lens epithelial cell line derived from a mature cataract was maintained as described previously [18]. The RNA samples for RT-PCR analysis were obtained from a healthy male Shiba dog (six years old).

\section{Measurement of arginine transport activity}

Radioactive ( ${ }^{3} \mathrm{H}-$ ) arginine was purchased from American Radiolabeled Chemicals (St Louis, MO, USA). Arginine uptake of LEC was measured as described previously [18]. Briefly, the cells were plated in $5 \times 10^{5}$ cells/6-well plate $24 \mathrm{~h}$ before the experiment. After washing the cells, a medium containing $100 \mu \mathrm{M}$ arginine with a radioisotope was added and incubated at $37^{\circ} \mathrm{C}$ for $10 \mathrm{~min}$. To study the effect of N-ethylmaleimide (NEM) on the transport activity, pretreatment with $0.2 \mathrm{mM} \mathrm{NEM}$ for 10 min was carried out before incubation with medium containing radiolabeled arginine. Uptake was terminated by washing with ice-cold phosphate-buffered saline. After solubilizing the cells with $1 \%$ SDS, the radioactivity was measured with a liquid scintillation counter, and the protein content was determined by the Micro BCA method. Arginine uptake was expressed as $\mathrm{nmol} / \mathrm{mg}$ protein min. Arginine uptake of canine red blood cells was measured as described elsewhere [11].

\section{Determination of cDNA sequence of canine CAT1}

Total RNA was isolated from the lens epithelial cell line established previously [24] using an RNA extraction solution (Isogen, Nippon Gene, Tokyo, Japan). The primers used in this study are shown in Table 1. The primer sets (s1 and a1) for amplification of a partial canine CAT1 cDNA were prepared from the conserved region sequences between humans and mice (DDBJ accession No. BC063303 and BC145779, respectively). RT-PCR amplification was performed employing a SuperScriptIII First-Strand Synthesis System kit (Invitrogen, Carlsbad, CA, USA) with Ex Taq Hot Start Version DNA polymerase (Takara Bio, Kyoto, Japan). The band was excised from the agarose gel and purified using a Wizard SV Gel and PCR Clean-Up System (Promega, Tokyo, Japan). The extracted and purified DNA were cloned into a pCR II-TOPO cloning vector (Invitrogen) and sequenced with a BigDye Terminator kit ver.3.1 Cycle Sequencing Kit (Applied Biosystems, Carlsbad, CA, USA). The nucleotide sequence obtained exhibited high similarities (90\%) to human CAT1 cDNA sequences. In order to determine the $3^{\prime}$ and $5^{\prime}$ regions of cDNA, RACE methods were carried out using a SMARTer RACE cDNA Amplification kit (Clontech, Mountain View, CA, USA) and a set of canine $C A T 1$ gene-specific primers (GSP1 and GSP2).

Western blot analysis of CAT1 protein in various canine tissues

The cell membrane of brain tissue for Western blot analysis was prepared as reported by Denker et al. [9]. In brief, LECs or cerebellums were homogenized at $4{ }^{\circ} \mathrm{C}$ in buffer containing $0.1 \mathrm{M} \mathrm{KCl}, 5 \mathrm{mM} \mathrm{Na}_{2} \mathrm{HPO}_{4} \mathrm{pH} 7.5$, $0.75 \mathrm{mM}$ Na-EGTA (pH 7.5), $1 \mathrm{mM}$ DDT, $5 \mathrm{mM} \mathrm{MgCl}_{2}$, $200 \mu \mathrm{g} / \mathrm{ml}$ phenylmethylsulfonyl fluoride, and $4 \mu \mathrm{g} / \mathrm{ml}$ leupeptin. Homogenates were centrifuged for $10 \mathrm{~min}$ to remove debris. The 1-vol. supernatant was laid over a 5 -vol. sucrose solution containing $0.8 \mathrm{mM}$ sucrose and $2 \mathrm{mM}$ Na-EGTA and was centrifuged at 32,000 $\times \mathrm{g}$ for $40 \mathrm{~min}$. Protein concentration of the pellet was determined by the BCA method, and was used for Western blot analysis as previously described [24]. Briefly, the 
Table 1. Sequences of oligonucleotides used in this study

\begin{tabular}{|c|c|c|c|}
\hline \multicolumn{2}{|c|}{ Primer } & Sequence $\left(5^{\prime}-3^{\prime}\right)$ & Expected product (bp) \\
\hline \multicolumn{4}{|c|}{ Oligonucleotide for cloning of canine $C A T 1$} \\
\hline & Sense & CGGGCTCAGCITACCTCTACAGCT & \\
\hline \multicolumn{4}{|c|}{ (Human CAT1: BC063303) } \\
\hline \multirow{2}{*}{$\begin{array}{l}\text { GSP1 (for 5' RACE) } \\
\text { GSP2 (for 3' RACE) }\end{array}$} & Antisense & GTCCGCGAGAACTCCGCAATGGGTTTGC & \\
\hline & Sense & AAGTATGCAGTGGCCGTCGGCTCCCTCT & \\
\hline \multicolumn{4}{|c|}{$\begin{array}{l}\text { Oligonucleotide for RT-PCR } \\
\text { Transcript }\end{array}$} \\
\hline \multirow[t]{2}{*}{ CAT1 (AB762780) } & Sense & CGGGCTCAGCITACCTCTACAGCT & \multirow[t]{2}{*}{392} \\
\hline & Antisense & AGTGCCAATGGACATGAGGTCCACCA & \\
\hline \multirow[t]{2}{*}{$G A P D H(\mathrm{AB} 038240)$} & Sense & ATC ACC ATC TTC CAG GAG CGA GA & \multirow[t]{2}{*}{192} \\
\hline & Antisense & GTC TTC TGG GTG GCA GTG ATG G & \\
\hline
\end{tabular}

The accession number is indicated in parentheses.

membranes were solubilized, electrophoresed into $12 \%$ polyacrylamide gels, and immunoblotted with a chemiluminescence autoradiograph. They were then treated with the primary antibody (rabbit anti-human CAT1, $\times 1,000$, Proteintech, Chicago, IL, USA), followed by the secondary antibody (anti-rabbit IgG $(\mathrm{H}+\mathrm{L})$ goat IgG Fab' HRP, $\times 20,000$, Seikagaku Corp., Tokyo, Japan). The CAT1 protein was detected with an ECL Plus a chemiluminescence detection system (GE Healthcare Bioscience, Chalfont, UK) and exposed to x-ray film.

\section{$R T-P C R$ analysis of CAT1 $m R N A$ in canine tissues}

In order to examine the expression of CAT1 mRNA in various organs of a dog, we performed RT-PCR using newly designed primers specific to canine $C A T 1$ (GSP1 and GSP2: Table 1). RT-PCR conditions were as follows: $94^{\circ} \mathrm{C}$ for $2 \mathrm{~min}$ and 30 cycles of three steps: $94^{\circ} \mathrm{C}$ for 10 $\mathrm{s}, 60^{\circ} \mathrm{C}$ for $10 \mathrm{~s}$ and $72^{\circ} \mathrm{C} 30 \mathrm{~s}$.

\section{Results}

Arginine transport activity of the canine lens epithelial cell line is shown in Fig. 1 (A). The transport activity was $0.424 \pm 0.047 \mathrm{nmol} / \mathrm{mg}$ protein min, while the presence of NEM, the inhibitor of CAT, significantly reduced arginine transport activity by $30 \%$. Red blood cells of the canine showed $17.33 \pm 0.46 \mu \mathrm{mol} / 1$ cells $\mathrm{h}$ arginine transport activity. Likewise, NEM reduced cationic amino acid transport activity by about $38 \%$ (B). Fig. 2A (left) shows the electrophoresis of RT-PCR products of canine CAT1 using primers (s-1 and a-1) that were well conserved between the human and rodent. The nucleotide sequence comprising 1070 bp showed high

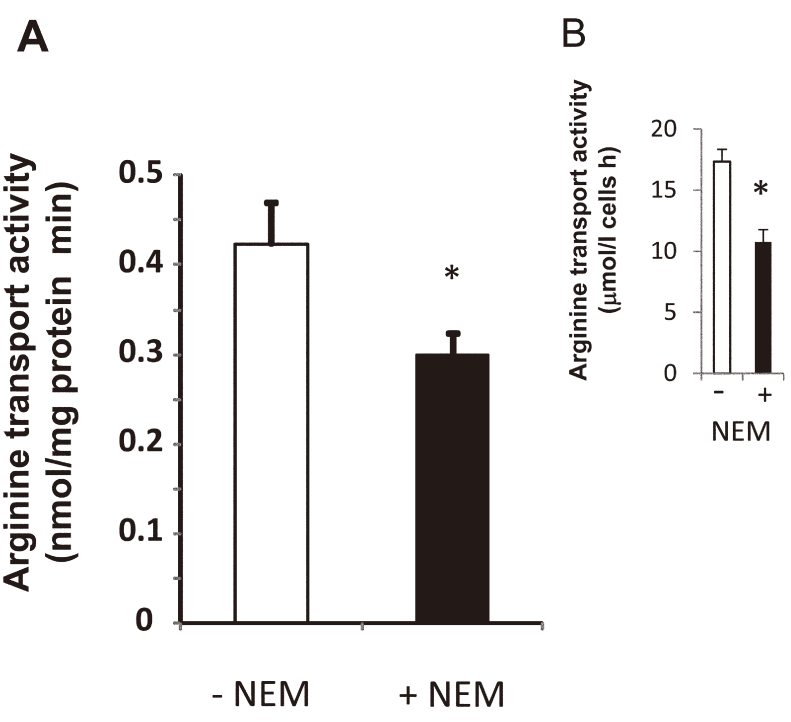

Fig. 1. Arginine transport activity of LECs (A) and red blood cells (B) in the presence (closed column) or absence (open column) of $0.1 \mathrm{mM} \mathrm{NEM}$. Values are means and SD of 4 individual experiments. Statistical differences between the treatments were determined by the Student's $t$-test $\left({ }^{*} P<0.05\right)$.

similarities (90\%) to mouse CAT1 cDNA sequences. The primers used for RACE were prepared from the sequence details listed in Table 1. Fig. 2A (right) also shows 3'and 5'RACE products. An obtained nucleotide sequence (DDBJ accession number AB762780) corresponding to a full-length canine $C A T 1$ cDNA was 2558 bp in length and contained an entire open reading frame of $1887 \mathrm{bp}$, encoding canine CAT1 having 629 amino acids and a theoretical mass of $68 \mathrm{kDa}$ (Fig. 2B). Figure 3 compares canine $C A T 1$ with those of reported in humans and rodents. The deduced amino acid sequence of CATI 
A

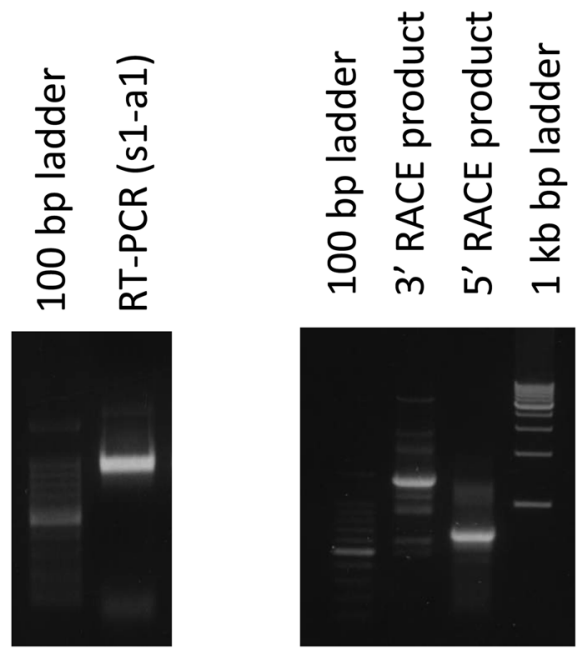

B 101 AATGTGGTGCATGGTGAAGAAGGTGTGATCCTGCTGGTGTGCACTGCCCGGGCTCTCTTGAGTCGGGGCCAGAAGCTGTCATCTCGCCCCTCCTGAGACA 100 M G C K V L L L 200
L AACATTGGCATCAGATACTGCGGCGGAAGGTTGTGGATTGCAGCCGGGAGGAGAGCCAGCTATCTCGCTGCTTGAACACTTTTGACCTGGTGGCGCTGG 300 $\begin{array}{llllllllllllllllllllllllllllllllllll} & \text { N } & \text { I } & G & \text { H } & \text { Q } & \text { I } & \text { L } & \text { R } & \text { R } & \text { K } & \text { V } & \text { V } & \text { D } & \text { C } & \text { S } & \text { R } & \text { E } & \text { E } & \text { S } & \text { Q } & \text { L } & \text { S } & \text { R } & \text { C } & \text { L } & \text { N } & \text { T } & \text { F } & \text { D } & \text { L } & \text { V } & \text { A } & \text { L G } & \text { G } \\ 301 & \text { GGGTGGGCAGCACCGCTGGGTGCCGGCGTGTATGTCCTGGCTGGAGCTGGTGGCCCGTGAGAATGCCGGCCCTGCCATTGTCAATCTCCTTCCTGATCGCAGC } & 400\end{array}$ 401 GCTGGCCTCGGTGCTGGCTGGCCTTCTGCTACGGCGAGTTTGGTGCTCGGGTCCCCAAGACAGGCTCGGCCTACCTCTACAGCTATGTCACTGTTGGGGAG

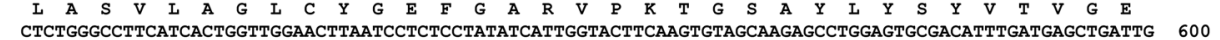
CTCTGGGCCTTCATCACTGGTTGGAACTTAATCCTCTCCTATATCATTGGTACTTCAAGTGTAGCAAGAGCCTGGAGTGCGACATTTGATGAGCTGATTG 601 GCAAACCCATTGCGGAGTTCTCGCGGACGCACATGGCTCTGAATGCCCCTGGAGTGCTGGCCGAAAACCCAGACATATTTGCTGTGATCATCATTCTCAT 700 $\begin{array}{lllllllllllllllllllllllllllllllllll}K & \text { P } & \text { I } & \text { A } & \text { E } & \text { F } & \text { S } & \text { R } & \text { T } & \text { H } & \text { M } & \text { A } & \text { L } & \text { N } & \text { A } & \text { P } & \text { G } & \text { V } & \text { L } & \text { A } & \text { E } & \text { N } & \text { P } & \text { D } & \text { I } & \text { F } & \text { A } & \text { V } & \text { I } & \text { I } & \text { I } & \text { L } & \text { I } & & \end{array}$ CTTAACAGGACTTTTAACTCTCGGTGTGAAAGAATCGGCCATGGTCAACAAAATATTTACTTGTGTCAATGTTCTGGTCTTGGGCTTCATTATGGTGTCA 800 \begin{tabular}{llllllllllllllllllllllllllllllllll} 
L & T & G & L & L & T & L & G & V & K & E & S & A & M & V & N & K & I & F & T & C & V & N & V & L & V & L & G & F & I & M & V & S & \\
\hline
\end{tabular}

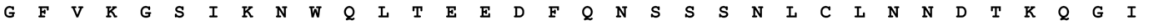
TATTTGGTGTTGGTGGATTCATGCCTTTTGGATTCTCCGGCGTCCTATCAGGGGCAGCAACCTGCTTCTATGCCTTCGTGGGCTTTGATTGCATCGCCAC 1000

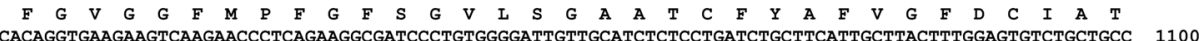
$T$ T CTCACACTCATGATGCCATACTTCTGCCTGGACAAGAACAGCCCCCTGCCTGACGCCTTCAAGCACGTGGGCTGGGAAGGTGCCAAGTATGCAGTGGCCG 1200

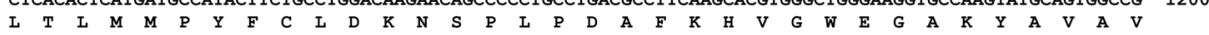
TCGGCTCCCTCTGTGCTCTTTCTACCAGTCTTTTAGGTTCCATGTTTCCCATGCCTCGAGTTATCTATGCCATGGCTGAAGACGGACTGCTATTTAAATT 1300

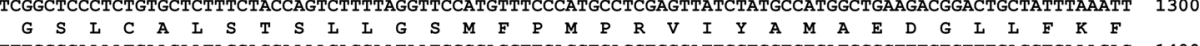
TIVGCCAAAATCAACAATAGGACCAAAACACCAATAATCGCCACGI \begin{tabular}{llllllllllllllllllllllllllllllllll}
$I$ & $A$ & $K$ & $I$ & $N$ & $N$ & $R$ & $T$ & $K$ & $T$ & $P$ & $I$ & $I$ & $A$ & $T$ & $L$ & $T$ & $S$ & $G$ & $A$ & $I$ & $A$ & $A$ & $V$ & $M$ & $A$ & $F$ & $L$ & $F$ & $D$ & $L$ & $K$ & $D$ & \\
\hline
\end{tabular}

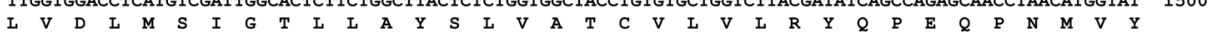

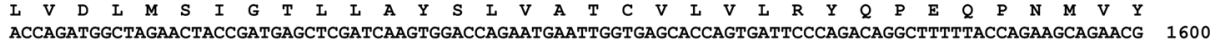

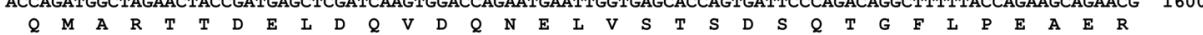
GTTTTCTTTGAAAACCATACTCTCACCCAAAAATATGGAGCCTTCCAAATTCTCCGGGCTGATTGTGAACATTTCAACCAGCCTCATAGCAATTCTTATC 1700

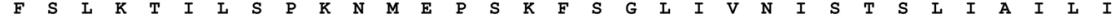
ATCACCTTCTGCATTTTGGCTGTGCTTGGAAAGGAGGCTCTGATAAAAGGGGAGTTGTGGGCAATCTTTGTGCTTACCATATCTGCACTTCTCTGCTTCC 1800 $\begin{array}{llllllllllllllllllllllllllllllllllll}I & T & F & C & I & L & A & V & I & G & K & E & A & I & I & K & G & E & I & W & A & I & F & V & \text { L } & T & \text { I } & \text { S } & A & \text { I } & \text { I } & C & F & \text { L }\end{array}$ 1801 TGGTCACAGTCATCATCTGGAGGCAGCCTGAGAGCAAGACCAAGCTTTCGTTTAAGGTGCCCI

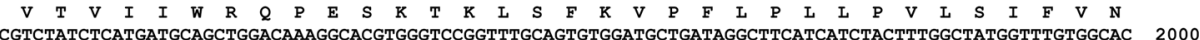
$\begin{array}{lllllllllllllllllllllllllllllllllll}V & Y & I & M & M & O & I & D & K & G & T & W & V & R & F & A & V & W & M & I & I & G & F & I & I & Y & F & G & Y & G & I & W & H\end{array}$ AGTGAGGAGGCGTCCCTGGCCACTGACCAAGCAAGGACTCCTGATGGCAATTTGGACCATTGCAAGTGACACGCAGCCCTACTCCCAGGGGTGGCAGCAG 2100

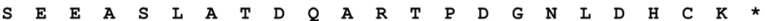

CCCGAGGGATGCCCGCAGAGTTCCTGGGAGCACCTCGCTCCCCCCACCAGTGCATCAGGACCCACCCACATCTACAGAGCCCCAATGCAGCAGAAGGTGC 2200 2201 AGCTACTTGAAATGCAGCCTCGGCCCACAACCCGTGTGTCCTGCCTAGACTTGCTCCACGTCAGGTGCACCACATCCCAGTCACCTCTGACAGCTCCCTG 2300 2301 GTGGGGGCACTTGGCTGCAGCTGGCCACTGTGGCTCCTGACATCCCTCTGAACAAAGCAAGCGGCTCCCGTCCTCACCAGCTCCGTGCCTGTGCTGCTG 2400 2401 TGTCCTCAGGCAGAATGGAGGTCACCTTCTCTTGTTACTTTGAAAAGCCAGGCCTCCCTCCCCAGGGACCATTCTGGTATTAAAAACATCCAAACTCCAG 2500 2401 TGTCCTCAGGCAGAATGGAGGTCACCTTCTCTTGTTACTTTGAAAAGCCAGGCCTCCCTCCCCAGGG

Fig. 2. PCR-based cloning of 5'- and 3'-stretched cDNA clones for canine CAT1 (A). Electrophoresis of RTPCR products of canine CAT1 using primers (s-1 and a-1) that are well conserved between humans and rodents (A) (left). 5'and 3'RACE products with the primers shown in Table 1 (right). Nucleotide and deduced amino acid sequences of the canine are shown (B). Full-length canine CAT1 cDNA was 2、558 bp in length and contained an entire open reading frame of $1,887 \mathrm{bp}$, encoding canine CAT1, which had 629 amino acids. The DDBJ accession number is AB762780. The termination codon is asterisked.

showed high similarities (92.1 and $88.6 \%$ ) to those of the human and mouse, respectively. Canine CAT1, as found in humans, possesses a seven-amino acid insertion between amino acid 224 and 225, and a one- amino acid insertion was found in between amino acid 231 and 232 of mouse CAT1. Canine CAT1 possessed 14 membranespanning domains, conserved consensus sequences for $\mathrm{N}$-glycosylation sites, and phosphorylation by protein 


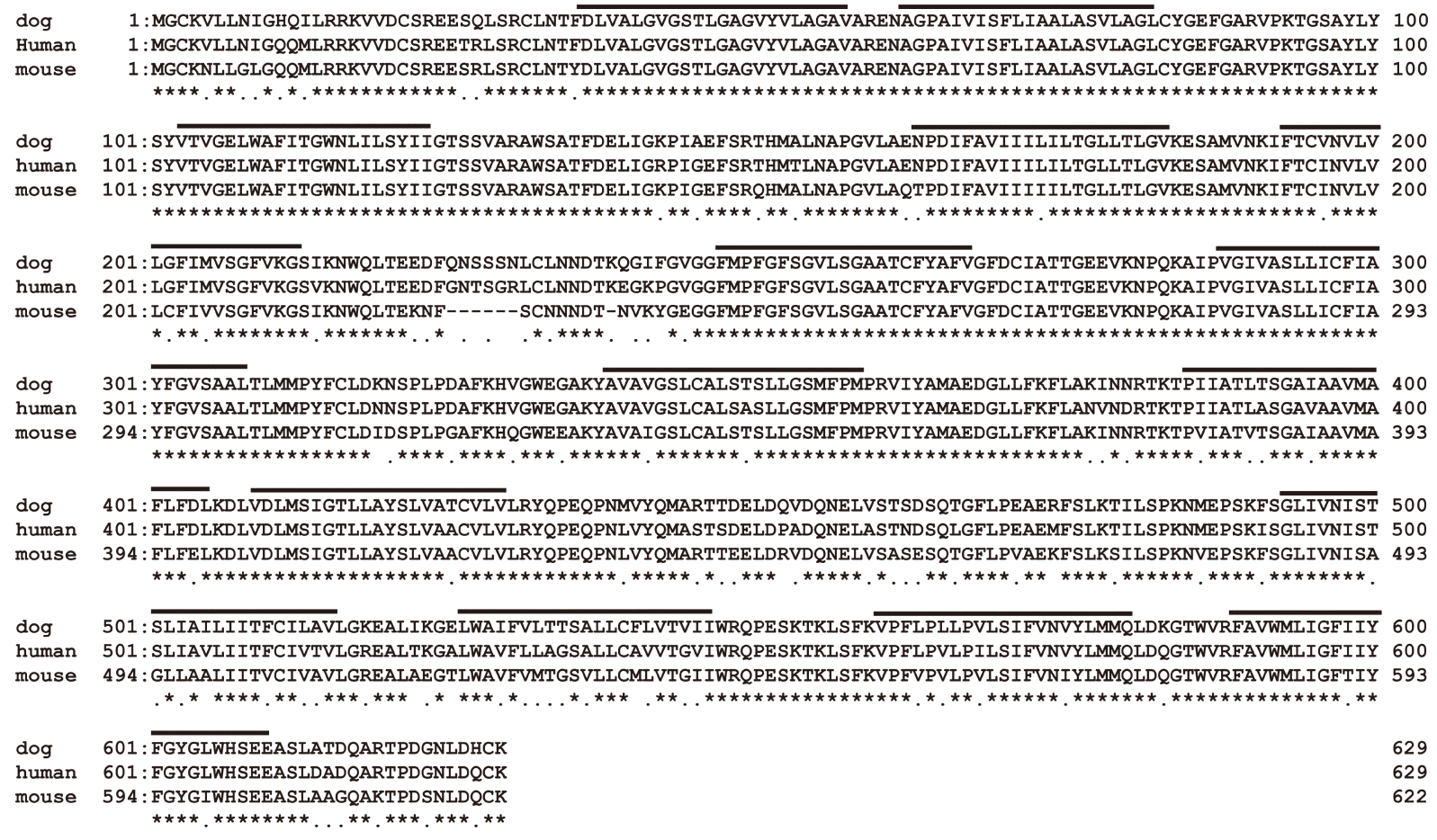

Fig. 3. Amino acid sequences of canine $C A T 1$ were compared with those of the human and mouse. Multiple sequence alignments were performed using the GENETYX software (ver. 10). Asterisks and dots indicate identical residues and conservative substitutions, respectively. Transmembrane domains are overlined.

kinase $\mathrm{C}$ (PKC) in a putative model according to Albritton et al. [1] (data not shown). Figure 4A shows RT-PCR analysis of CAT1 expression in canine various tissues. A single distinct band was observed in all the tissues examined including the liver. Western bolt analysis using anti-human CATl detected a band at $70 \mathrm{kDa}$ in the membrane of LECs (Fig. 4B).

\section{Discussion}

In this study, we investigated the cationic amino acid transport activity in canine LEC, found the NEM-sensitive Arg transport component, and determined a fulllength cDNA sequence of canine CAT1. The deduced amino acid sequence of canine CATl showed high similarities to those of the human and mouse. $\mathrm{Glu}^{107}$ was reported to be essential for the transport activity of $\mathrm{mCAT1}[7]$ and it was also conserved in canine. RT-PCR analysis confirmed that $C A T 1$ was detected in all tissues examined including the liver. Western blot analysis using anti-human $C A T 1$ detected the band in $70 \mathrm{kDa}$ in the membrane protein of LECs. It was reported that CAT1 is expressed almost ubiquitously except in the adult liver, but its expression level varies considerably in dif- ferent tissues and cell types [20]. RT-PCR analysis showed that $C A T 1$ expression was observed in all tissues examined including the liver in the canine (Fig. 4A).

Cationic amino acids supplied through the CAT proteins feed into protein synthesis and other enzymatic reactions dependent on them, including synthesis of nitric oxide (NO), urea, creatine and agmatine from arginine or synthesis of polyamines, proline and glutamine from ornithine. CAT1 is the major cationic amino acid transporter in most cells. Notably, homozygous CAT1 knockout mice die on day 1 after birth, are $25 \%$ smaller than their wild-type littermates, and suffer from severe anemia, while the heterozygous mice exhibit no phenotype abnormality [25]. CAT1 expression can be modulated by a variety of stimuli including cell proliferation, growth factors, cytokines, and hormones. The transport activity of human CAT1 is decreased after activation of protein kinase $\mathrm{C}$ (PKC) in human endothelial cells, indicating posttranslational regulation [13]. CAT1 activity can also be modulated by interaction with cytoskeletal proteins [27]. Although there are some cationic amino acid transport systems, CAT is the only NEM-sensitive transport system [10]. So far it has not been determined whether or not NEM inhibits all CAT isoforms, and the 


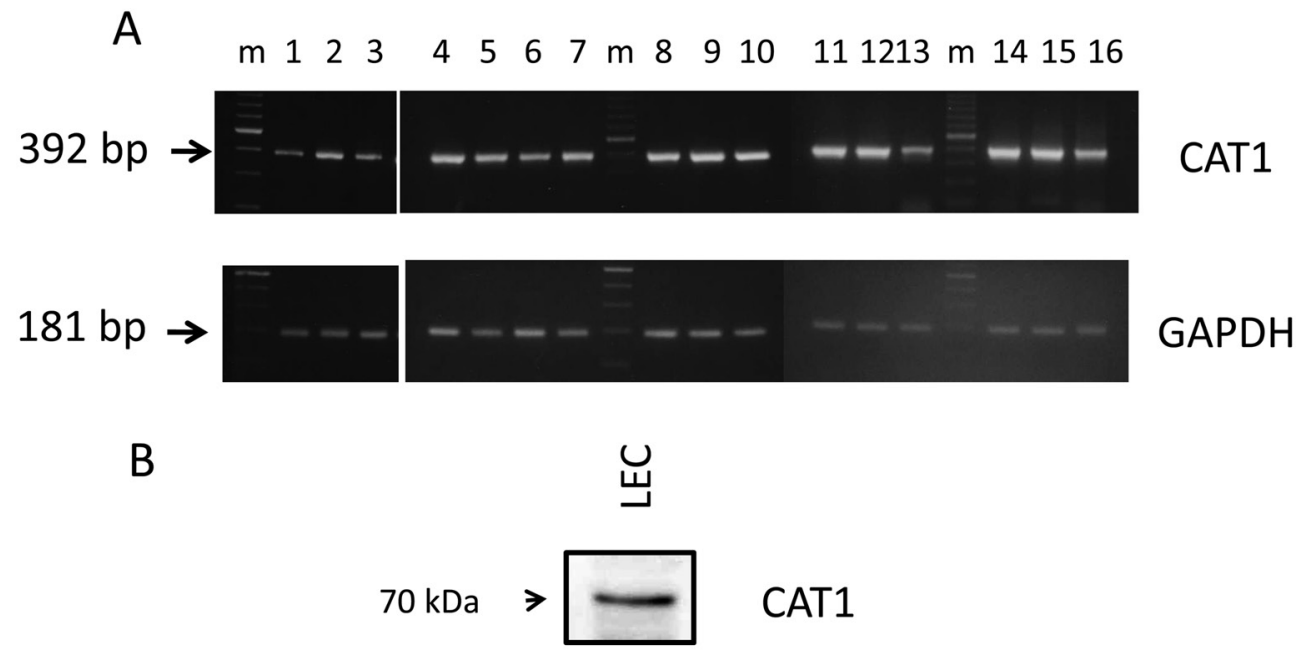

Fig. 4. RT-PCR analysis of canine $C A T 1$ mRNA in various dog tissues (A). Integrity of RNA was examined uing glyceraldehyde-3-phosphate dehydrogenase $(G A P D H)$. Lane 1, nictitating membrane gland; lane 2, lacrimal grand; lane 3, LECs; lane 4, cerebellum; lane 5, trachea; lane 6, kidney; lane 7, liver; lane 8 , salivary gland; lane 9 , lung; lane 10, testis; lane 11, heart; lane 12, ileum; lane 13 , colon; lane 14, bladder; lane 15, skeletal muscle; lane 16, placenta. Western blot analysis of canine CAT1 expression in the LEC membrane $(20 \mu \mathrm{g})$ using anti-human CAT1 antiserum (B).

cysteine residues in the CAT proteins sensitive to NEM have not yet been identified.

The ocular surface is constantly exposed to environmental pathogens, particularly those vulnerable to infection. An advanced immune defense system is therefore essential to protect the eyes from microbial attack. Defensins are a family of highly conserved arginine- and lysine-rich cationic proteins, which have an important role in combating microbial infection. They are essential components of the innate immune system and are the first line of defense against microbials on the ocular surface [12]. Defensins are attracted by the microbial membrane's negative charge and cause disruption by first binding and then intercalating, to form pores that destroy the integrity of the lipid layer. This dissipates the membrane potential and kills the cells [28]. Two groups of defensins are recognized in mammalians: $\alpha$-defensins, produced by neutrophils and the Paneth cell of the small intestine, and $\beta$-defensins secreted by epithelial-derived tissues. $\beta$-defensin production at mucosal surfaces is an important part of the innate immune system. In order to produce the defensins, the cells forming them require large amounts of L-arginine and lysine.

In this report, we investigated the cationic amino acid transport activity in canine LECs, found the NEM-sensitive Arg transport component, and determined a fulllength cDNA sequence of canine $C A T 1$. The deduced amino acid sequence of canine CAT1 showed high similarities to those of the human and mouse. RT-PCR analysis confirmed that $C A T 1$ was ubiquitously detected in all tissues examined including the liver. Interestingly, in diseases accompanied by L-arginine deficiency [16, 22], e.g., psoriasis, dry skin, and diabetes of rheumatoid arthritis, there is a significant association with increased $\beta$-defensin production as well as dry eye in humans [23, $26]$. The data clarified in this paper may facilitate study of the cationic amino acid metabolism and disease on the canine ocular surface. We will next investigate the relationship between $\beta$-defensin expression and CAT1 activity on microbial infectious conditions in LECs.

\section{Acknowledgments}

This study was supported in part by a Grant-in-Aid to HO from the Ministry of Education, Culture, Sports, Science and Technology of Japan (No. 19580376) and a research project grant awarded by the Azabu University Research Services Division.

\section{References}

1. Albritton, L.M., Tseng, L., Scadden, D., and Cunningham, J.M. 1989. A putative murine ecotropic retrovirus receptor gene encodes a multiple membrane-spanning protein and 
confers susceptibility to virus infection. Cell 57: 659-666. [CrossRef] [Medline]

2. Babizhayev, M.A. and Costa, E.B. 1994. Lipid peroxide and reactive oxygen species generating systems of the crystalline lens. Biochim. Biophys. Acta 1225: 326-337. [CrossRef] [Medline]

3. Christensen, H.N., Handlogten, M.E., Lam, I., Tager, H.S., and Zand, R. 1969. A bicyclic amino acid to improve discriminations among transport systems. J. Biol. Chem. 244: 1510-1520. [Medline]

4. Christensen, H.N. 1990. Role of amino acid transport and countertransport in nutrition and metabolism. Physiol. Rev. 70: 43-77. [Medline]

5. Closs, E.I., Albritton, L.M., Kim, J.W., and Cunningham, J.M. 1993. Identification of a low affinity, high capacity transporter of cationic amino acids in mouse liver. J. Biol. Chem. 268: 7538-7544. [Medline]

6. Closs, E.I., Gräf, P., Habermeier, A., Cunningham, J.M., and Förstermann, U. 1997. Human cationic amino acid transporters hCAT-1, hCAT-2A, and hCAT-2B: three related carriers with distinct transport properties. Biochemistry 36: 64626468. [CrossRef] [Medline]

7. Closs, E.I. 2002. Expression, regulation and function of carrier proteins for cationic amino acids. Curr. Opin. Nephrol. Hypertens. 11: 99-107. [CrossRef] [Medline]

8. Closs, E.I., Lyons, C.R., and Kelly, C. 1993. Cunningham JM. Characterization of the third member of the MCAT family of cationic amino acid transporters. Identification of a domain that determines the transport properties of the MCAT proteins. J. Biol. Chem. 268: 20796-20800. [Medline]

9. Denker, B.M., Kwon, E.D., Kuhajda, F.P., and Agre, P. 1988. Identification, purification, and partial characterization of a novel $\mathrm{Mr}$ 28,000 integral membrane protein from erythrocytes and renal tubules. J. Biol. Chem. 263: 15634-15642. [Medline]

10. Devés, R. and Boyd, C.A. 1998. Transporters for cationic amino acids in animal cells: discovery, structure, and function. Physiol. Rev. 78: 487-545. [Medline]

11. Devés, R., Angelo, S., and Chávez, P. 1993. N-ethylmaleimide discriminates between two lysine transport systems in human erythrocytes. J. Physiol. 468: 753-766. [Medline]

12. Garreis, F., Schlorf, T., Worlitzsch, D., Steven, P., Bräuer, L., Jäger, K., and Paulsen, F.P. 2010. Roles of human beta-defensins in innate immune defense at the ocular surface: arming and alarming corneal and conjunctival epithelial cells. Histochem. Cell Biol. 134: 59-73. [CrossRef] [Medline]

13. Graf, P., Forstermann, U., and Closs, E.I. 2001. The transport activity of the human cationic amino acid transporter hCAT11 is down-regulated by the activation of protein kinase C. $B r$. J. Pharmacol. 132: 1193-1200. [CrossRef] [Medline]

14. Hazlett, L.D., Mc, D., Clellan, S., Goshgarian, C., Huang, X., Thakur, A., and Barrett, R. 2005. The role of nitric oxide in resistance to $P$. aeruginosa ocular infection. Ocul. Immunol. Inflamm. 13: 279-288. [CrossRef] [Medline]

15. Hoffmann, G., Schobersberger, W., Rieder, J., Smolny, M., Seibel, M., Fürhapter, C., and Fritsch, P. 1999. Human dermal microvascular endothelial cells express inducible nitric oxide synthase in vitro. J. Invest. Dermatol. 112: 387-390.
[CrossRef] [Medline]

16. Jaeger, K., Paulsen, F., and Wohlrab, J. 2008. Characterization of cationic amino acid transporters (hCATs) 1 and 2 in human skin. Histochem. Cell Biol. 129: 321-329. [CrossRef] [Medline]

17. Kakuda, D.K., Finley, K.D., Dionne, V.E., and MacLeod, C.L. 1993. Two distinct gene products mediate y+ type cationic amino acidtransport in Xenopus oocytes and show different tissue expression patterns. Transgene 1: 91-101.

18. Kanemaki, N., Saito, M., Onda, K., Maruo, T., Ogihara, K., Naya, Y., Morishita, T., and Ochiai, H. 2012. Establishment of a lens epithelial cell line from a canine mature cataract. Exp. Anim. 61: 41-47. [CrossRef] [Medline]

19. Kavanaugh, M.P., Wang, H., Zhang, Z., Zhang, W., Wu, Y.N., Dechant, E., North, R.A., and Kabat, D. 1994. Control of cationic amino acid transport and retroviral receptor functions in a membrane protein family. J. Biol. Chem. 269: 15445-15450. [Medline]

20. Kim, J.W., Closs, E.I., Albritton, L.M., and Cunningham, J.M. 1991. Transport of cationic amino acids by the mouse ecotropic retrovirus receptor. Nature 352: 725-728. [CrossRef] [Medline]

21. Liew, F.Y. and Cox, F.E.G. 1991. Nonspecific defence mechanism: the role of nitric oxide. Immunol. Today 12: A17A21. [CrossRef] [Medline]

22. Lucotti, P., Setola, E., Monti, L.D., Galluccio, E., Costa, S., Sandoli, E.P., Fermo, I., Rabaiotti, G., Gatti, R., and Piatti, P. 2006. Beneficial effects of a long-term oral L-arginine treatment added to a hypocaloric diet and exercise training program in obese, insulin-resistant type 2 diabetic patients. Am. J. Physiol. Endocrinol. Metab. 291: E906-E912. [CrossRef] [Medline]

23. McDermott, A.M. 2004. Defensins and other antimicrobial peptides at the ocular surface. Ocul. Surf. 2: 229-247. [CrossRef] [Medline]

24. Ochiai, H., Saito, M., Maruo, T., and Kanemaki, N. 2010. Molecular cloning of canine excitatory amino acid transporter 5 and its detection in primary lens epithelial cells. Exp. Anim. 59: 449-457. [CrossRef] [Medline]

25. Perkins, C.P., Mar, V., Shutter, J.R., del Castillo, J., Danilenko, D.M., Medlock, E.S., Ponting, I.L., Graham, M., Stark, K.L., Zuo, Y., Cunningham, J.M., and Bosselman, R.A. 1997. Anemia and perinatal death result from loss of the murine ecotropic retrovirus receptor mCAT-1. Genes. Dev. 11: 914-925. [CrossRef] [Medline]

26. Rahman, A., Yahya, K., Ahmed, T., and Sharif-Ul-Hasan, K. 2007. Diagnostic value of tear films tests in type 2 diabetes. J. Pak. Med. Assoc. 57: 577-581. [Medline]

27. Zharikov, S.I., Sigova, A.A., Chen, S., Bubb, M.R., and Block, E.R. 2001. Cytoskeletal regulation of the L-arginine/ NO pathway in pulmonary artery endothelial cells. Am. J. Physiol. Lung Cell Mol. Physiol. 280: L465-L473. [Medline]

28. Zou, G., de Leeuw, E., Li, C., Pazgier, M., Li, C., Zeng, P., Lu, W.Y., Lubkowski, J., and Lu, W. 2007. Toward understanding the cationicity of defensins. Arg and Lys versus their noncoded analogs. J. Biol. Chem. 282: 19653-19665. [CrossRef] [Medline] 